\title{
Ding Zuyi's Education Thoughts and Chinese Traditional Culture
}

\author{
Hongqiao Song \\ Xi'an Fanyi University \\ Xi'an, China 710105
}

\begin{abstract}
Mr. Ding Zuyi has inherited the fine tradition of Zhongnan education, and carried forward the noble education idea. He has followed the excellent tradition of utilitarianism of Guan School, and taken the talent training mode of "foreign language, profession and modernized skills" and "profession, foreign language and modernized skills". Learning from the management model of Zhongnan religious culture, it uses the quasi-military management on students. It helps the helpless, makes talent out of the ambitious and creates glory from the brave. Thus, it makes the school become "ark of hope and forge for cultivating temperament". It has trained hundreds of thousands of high-quality applied talents for the country.
\end{abstract}

Keywords-Ding Zuyi; education thought; Chinese traditional culture; noble education

\section{INTRODUCTION}

In early 1990s, when many colleges and universities in Xi'an moved to Xi'an downtown from the surrounding or remote areas, Professor Ding Zuyi founded Xi'an Fanyi University and officially moved it to Taiyi Palace Town, Changan District, at the foot of quiet Zhongnan Mountain from prosperous Tumen, Weiyang District of Xi'an City. The predecessor of Xi'an Fanyi University is Xi'an Vocational College of Translation and Interpretation. It was formally and completely moved to the foot of Zhongnan Mountain in 1992. In 1995 it was formally approved by the Department of Education and renamed as Xi'an Fanyi University.

Mr. Ding Zuyi has inherited the fine tradition of Zhongnan education and carried forward noble education ideas. He has followed the excellent tradition of utilitarianism of Guan School, and taken the talent training mode of "foreign language + profession + modernized skills" and "profession + foreign language + modernized skills". Learning from the management model of Zhongnan religious culture, it uses the quasi-military management on students. It helps the helpless, makes talent out of the ambitious and creates glory from the brave. Thus, it makes the school become "ark of hope and forge for cultivating temperament". It has trained hundreds of thousands of high-quality applied talents for the country. The brilliance of Mr. Ding Zuyi's education thought can be seen

Project fund: Supported by the scientific research program of Shaanxi Provincial Education Department (Item number: 17JK0987)

Project of Educational Science Planning in Shaanxi Province, Research on Training Mode of Core Competence of Engineering Management Talents in Private Universities (SGH17H480) from the following three aspects.

\section{EDUCATION CONCEPTS}

During the Western Zhou Dynasty, the official education institutions were set beside the Fenghe River, at the foot of Zhongnan Mountain. It carried forward the philosophy of feudal ethnics and rites. In the Spring and Autumn and Warring States period, the rite and music system was collapsed Academic thoughts shined with glory, and Confucianism came into being. The main category of Confucianism is "righteousness", and it explains "rite" with "righteousness". In inner aspect, "righteousness" highlights initiative and independence of individual personality, and is closely corresponded and connected with external humanism. On the basis of righteousness, Confucius consciously or unconsciously created an organic whole of blood, psychology, humanity and personality and developed it into an ideological model characterized by practical reason. On the basis of consanguinity, the core of social parenthood love with "human touch" is expanded into external humanitarianism and inner ideal personality. And this constitutes the unique culture of the Chinese nation - the embryonic form of the psychological structure. This psychological pattern directly or indirectly has become the theoretical source and realistic basis of Ding Zuyi's noble education thought, and has been developed and sublimated in practice, which are embodied in the following aspects.

\section{A. The Second Hope Project}

"Helps the helpless, makes talent out of the ambitious and creates glory from the brave" is the main goal of the second hope project. It is also the unlimited expansion and sublimation of this concept. At the beginning of schooling in 1988, he first put forward the schooling concept of "the second hope project". Ding Zuyi said: "to help the poor children attend school is a hope project, and to help students failed to pass the college entrance exam go to school is also a hope project. It is a great service to mankind to help these failed students go to school. Because of this concept in my heart, I decided to embark on this desolate virgin land in private colleges". Following this, he further explained the connotation of "second hope project". He said: "the student failed to pass the college entrance exam is like water of seventy or eighty degree. If we add some firewood and give them an opportunity to receive higher education in private universities, they can 
become talents of higher occupation technology. They also are the future hope of Chinese nation. This is our 'second hope project"'.

The education concept shows passionate feelings of $\mathrm{Mr}$. Ding Zuyi to share worries for the country, solve problems for the society and overcome difficulties for parents and help students become useful. In the schooling practice, Ding Zuyi strictly implements this education concept. He constantly enriches, develops and perfects the connotation of the second hope project, and innovates the implement strategies. He said: "to run school, first of all is to love students. Education practitioners, including both teachers and other staff, shall not only impart knowledge unreservedly to them, but also shall help them become talent with merits and ability and the pillars of society. To reach this goal, we shall aim at the needs of students and serve them and meet their needs to the furthest". It can also be the education concept in the second hope project. After repeat demonstration from the long-term perspective of talent training, it is constantly deepened and refined in practical development.

Mr. Ding Zuyi's education concept "the second hope project" has a guiding significance and an important role in promoting the steady and healthy development of Xi'an Fanyi University.

\section{B. Not Doing School Business and Adhering to the Educational Philosophy of Socialist Public Welfare}

Early in 1990, Mr. Ding Zuyi wrote "Adhere to the Socialist Schooling Orientation and Explore the Social Forces to Run School". It clearly explained the main connotation of not doing school business and adhering to the education philosophy of socialist public welfare. First, the whole process should involve around the goal of ensuing and improving teaching quality and cultivating talents for the society. Second, the schooling group, especially the principal responsible for the school, shall have the spirit of selfless dedication and the ability to innovate. Third, the income flow shall be used to improve the teaching conditions, rather than for private benefits. It is an important symbol to measure the socialist schooling direction. Fourth, the founder shall implement the education in an all-round way - morally, intellectually and physically, shall has a high sense of responsibility and adheres to the soul of socialist schooling direction. Then, Mr. Ding Zuyi combined the overall development reality of private colleges and the consistent practical spirit of translation and profoundly pointed out that: school runners shall define the public property of schooling; tuitions from students shall be used for teaching. It shall not be operated for benefits, and pursue return. We don't do school business. We shall help student become talent to the furthest.

After Mr. Ding Zuyi's death, the successor and chairman of Xi'an Fanyi University and the first session of leadership have followed the schooling spirit of Mr. Ding Zuyi, not doing school business and adhering to the socialist school direction of socialist public welfare. They unswervingly adhere to the practice of the noble schooling concepts: "helps the helpless, makes talent out of the ambitious and creates glory from the brave" and "noble education". They applied Xi'an Fanyi
University as a "non-profit" private college" that "does not seek a reasonable return".

\section{The Practical Development of Twelve-character Policy}

The twelve-character guide policy is "study hard, conduct oneself, be civilized, carry love, implement reform and advance bravely". It was first put forward by Mr. Ding Zuyi in the first middle-level cadres meeting of the new semester in Xi'an Fanyi University. It is a brief summary and forwardlooking thinking on schooling practice and education experience of Xi'an Fanyi University since its found in Oct. 1987, and further explanation of its schooling concept and educational spirit. It has played an important role in effective promotion of all works in the school, especially in the face of new transformation for greater development.

According to the preliminary explanation of Mr. Ding Zuyi, "study hard" includes to study all relevant professional books as well as extracurricular humanistic classics and look through or carefully read relevant knowledge in network media, reflection on self learning with the combination of reality. But it mainly refers to professional knowledge students have majored. Now the employment situation is severe. One shall first be able to raise himself, and then develop. School shall start construction from "climate for teaching" and "climate for learning" and teach students how to "conduct themselves" and transform from "limiting students to do something" to "encouraging students to do something".

Mr. Ding Zuyi has talked about his views on how to develop students' personality and give full play to their advantages: there is no limit in study and scientific research. One can enjoy the wings of imagination. In the public domain, one shall standardize themselves according to their social roles. I don't want to blindly copy other countries' liberal values. Thousands of years of Chinese traditional culture has been in the forefront of the world. Chinese civilization is inexhaustible. He thought, to care every student including their learning, life and growth is to "carry love" and a "civilization". But schools do not do school business and use all money from students on themselves and hold the flag of "the second hope project". It is a greater realm to "carry love" and "be civilized" which can attract more young and ambitious people to study and make them useful. So, schools shall strictly implement the mode of giving failed students opportunities to go to school and make higher vocational school into quasi-undergraduate college, strengthen the building of hardware to improve learning atmosphere of students and boldly implement reform and carry out the strategy of "relatively high-quality student source".

"To broaden the way of higher vocational school, to develop undergraduate college, to carry forward characteristics and to strive for higher level" is an important guide of Xi'an Fanyi University in practice. It nicely explains the meaning of "implementing reform" and "advancing bravely" Mr. Ding Zuyi put forward in the early time. After that, Xi'an Fanyi University opened a new road. Every year the university selects students of good character and scholarship who dare to give up traditional academic examination and traditional diploma and devote to liberal professions and independent entrepreneurs, and have certain economic capacity to study 
abroad and take advanced study in the translation research and study college of Xi'an Fanyi University from ten thousands of students out of the national unified entrance exam plan. Such great reform and leap advance examples have reflected the faithful practice of Xi'an Fanyi University on the twelvecharacter policy and its spiritual essence.

Mr. Ding Zuyi also believed that the university shall start from reality and take a distinctive schooling road that can reflect characteristics of private school and develop sustainably. New thoughts and concepts of Mr. Ding Zuyi in each development stage are reflected in "the second hope project", "non-for-profit socialist schooling direction", "study carefully and be an upright person", "love our country, love our school and determine to be a useful person", "direct all reforms with the view of scientific development and promote the development of civilization by teaching and construct a harmony campus with humanistic spirit", "study hard, conduct oneself, be civilized, carry love, implement reform and advance bravely". They all reflect his education thoughts and concepts and spirits on the practice and theoretical exploration of private education cause.

\section{Noble Education Thought}

Noble education is a new education concept put forward by Chinese outstanding modern educator Mr. Ding Zuyi at the end of his life. Under new historical conditions, it has an importance guiding value and practical significance in further optimizing the school environment, purifying the school ethos, improving the education system, and promoting education reform and sustainable and healthy education in a virtuous circle.

Mr. Ding Zuyi first put forward "noble education" in speech in the first cadre meeting of the new semester in early 2011. Afterwards, he received interviews of many large media, including sohu.com, Chinese net, Chinese education network, and said "carry out noble education that can make you proud" in various educational and academic meetings. According to main spirits of his speech, some key points can be summed up about the scientific connotation of Mr. Ding's noble education. First of all, the first prerequisite for noble education is "noble policies". We should "focus on cultivating the hope of the future and creating a new generation". Second, it is a noble undertaking for the rejuvenation of the Chinese nation and the healthy development of school running and education. Third, organizers shall have noble character. The school shall have definite schooling aim, purpose, reshape the core values of education, resist corruption, adhere to the public welfare of education and resolutely oppose the absolute utility and industrialization of education. Fourth, teaching methods should be noble. Carry forward good virtues of Chinese traditional education, like "providing education for all people without discrimination", "being a good teacher to transmit wisdom, impart knowledge and solve doubts" and "respecting teachers". Put students in first place, implement teaching scientifically, manage strictly and cultivate students diligently, and cultivate qualified talents with noble personality, noble character and noble spirit. Fifth, the purpose of teaching should be noble. Teachers should carry forward the spirit of "candle", serve as an example, and don't lust for wealth and position. Be integrity, fair and upright. A teacher team with noble character, noble personality and spirit shall be build to serve students wholeheartedly and help them succeed.

"Noble" means good moral and good quality. Book of Study explains "education" that "educators shall have a nose for advantages of students and cultivate them carefully, and help students overcome their shortcomings". Doctrine of Mean says "method for study is education". Xunzi says "to guide people with kind methods is education". Mencius said "get talents of the country and cultivate them. It is one of three great joys in life". He is the first ancient sage who connected “教” with “育”. According to our ancient education concepts, noble education of Mr. Ding can be summed up: respect the law of education development, attach importance to the cultivation of teachers and students with noble personality, noble character and noble sentiment, and with high quality and high skills. In short, it is to run school with noble thoughts, educate people with noble character and influence people with noble personality.

Therefore, Mr. Ding Zuyi put forward the schooling concept of "noble education" in this new age. It is closely associated with our society, economy, politics, culture and science. It is an education thought that set according to our socialist system and education system, and the principle of learning for practice and utilitarianism. It is also closely linked with folk customs in Zhongnan area.

\section{EDUCATION AIM}

When he talks about the tradition of national education, Mr. Ding Zuyi said, "Since ancient times, the private education of the Oriental has a long history. China has a population of $1 / 4$ in the world. Educator Confucius has established private education and education concept in China more than 2500 years ago. From that time of Confucius, education became the sacred mission of our Chinese nation. Xi'an Fanyi University has been adhering to the fine tradition of our motherland, and has always focused on the theme of human - 'love and education'". This educational thought and educational idea of Mr. Ding Zuyi can find the root in Chinese traditional education culture and Confucianism.

In the Spring and Autumn and Warring State period, "the rite and music system collapsed". With violent and sudden change of society, human's academic thoughts shined with splendor. The most influential educational thoughts in area of Zhongnan Mountain are of Confucianism and Taoism. Confucius advocated the gentleman personality, thought that the importance of education is neither in speech nor discussion, but in action. Mr. Ding Zuyi is the model of gentleman personality. "Gentleman shall be slow in words, and quick in action" (Analects of Confucius, Li Ren 4: 24). "Listen one's words and watch his behavior" (Analects of Confucius, Gong Zhichang 5: 10). As the president of private university, Mr. Ding Zuyi decisively abandoned the mainstream fashion of private colleges and universities relying on the schooling pattern of rental schoolhouses, took the lead in building own schoolhouses with heavy investment. Under the guidance of Chinese traditional education theory and innovation education idea, he based on "the second hope project" and the student- 
oriented education purpose, scientifically positioned the self development and training purpose, summarized schooling experience, give up traditional teaching mode of single profession in regular colleges and universities in face of great trend in market economy reform, and put forward the education mode of training "compound and applied foreignrelated talents with double professions" in continuous development and practice in Xi'an Fanyi University. He innovatively raised the professional talent training mode of "profession + foreign language + modernized skills" and "foreign language + profession + modernized skills", and launched and strictly implemented the "five-type" quasimilitary management system highly responsible for students. This is the known "Ding-style education mode". This education mode is the interpretation and practice of "practical reason" in the traditional Chinese education culture. It has broadened the way of innovation and enriched the connotation of practice for the development of Chinese private education cause, enhanced the educational specifications and levels, and meanwhile, it has also accelerated the development of education and promoted the cultivation of talents, and injected vitality.

In 1992, Mr. Ding Zuyi overrode all objects and held his opinion to move the university from Xi' an City to the foot of Zhongnan Mountain. It indicates the fate of Xi'an Fanyi University with Guan School and Zhongnan culture. Guan School was founded by Zhang Zai in the Northern Song Dynasty, and his academic thought was called "Guan School". Hengqu Institute was established by Zhang Zai. He attached importance to righteousness and taught his academic thoughts mainly. It was a private educational institution. Guan School was started from the Song Dynasty and ended at the beginning of Ming Dynasty. With a time span of more than eight hundred years, it has shaped the regional culture of Shaanxi and Chinese traditional culture with a distant origin and in order. It has a profound impact on Mr. Ding Zuyi and Xi'an Fanyi University he founded.

The compound and applied foreign-related talent training mode with double professions, initiatively created by $\mathrm{Xi}$ 'an Fanyi University has been followed by many colleges and universities. It inherits and carried forward the realistic style of Guan School in utilitarianism. Compared with traditional education modes of public colleges and universities, the mode of Xi'an Fanyi University has six major connotation characteristics, including compliance in curriculum setting, practicability in training target, foreign-affair concerning characteristic in employment, universality in application scope, practicalness in teaching link and innovation in teaching reform. This talent training mode fully embodies the pursuit of practical value in vocational skilled personnel training. On May 29, 2009, Mr. Ding Zuyi founded Shaanxi Zhongnan Society with the idea of "holding a red silk to connect Zhongnan". He achieved his second great dream. Touched by Zhang Zai's "reconstruct spiritual value for the society, establish the meaning of life for people, inherit tradition from former saints and pursue eternal peace for development, he established the aim of the society: "adhere to excellent Chinese tradition and culture, set correct academic thoughts and pave new ways for education and develop for future China". The establishment of the society comes from Mr. Ding Zuyi's reflection and thought on education for a long time as well as the material and humanistic resource deposit. He hope to remove tangible walls of school in thought culture taking the society as an opportunity. He runs school and helps thousands of students nurture in cultural academic atmosphere. With the splendor of long-standing Chinese culture, he made great contribution to the great rejuvenation of the Chinese culture.

Mr. Ding Zuyi has inherited and developed Confucius's educational thought. He always follows the educational thought mode characterized by practical rationality. He didn't seek resolution in theory and solve philosophical issues in debate, but finds results from reality. It is also a major feature of Zhongnan private education.

\section{MANAGEMENT Mode}

In teaching, Confucius was good at guidance. He aroused students' learning enthusiasm and paid attention to the cultivation of students' ability of independent thinking. He advocated "less talk and more action", "guiding students patiently", "gaining new knowledge by reviewing the old". In addition, he paid attention to students' individual difference and learning process and attitude, and advocated "teaching student in accordance with their aptitude". He also asked his students to combine "learning with thinking". In the whole education process, he was strict but full of love. He implemented rites with righteousness. It can be seen from his reply to Zai Wo "three years of mourning" (Analects of Confucius, Yang Huo 17: 21).

The reply of Confucius to Zai Wo shows that he included the traditional rite of "three years of mourning" into the life reason of parent's love directly. He attributed the foundation of rite to the dependence in one's heart, thus the restraint of rite becomes the inner requirement of human. The rigid constraint is promoted to the consciousness of life concept. A religious and mystery thing was made into our daily feeling, so as to integrate the ethical norms and psychological demands (History of Ancient China, Li Zehou, page 15-18). Confucius did not guide human's thymopsyche to external worship of object or mysterious realm, but integrated it into world relations with parent-child relationship as the core. The three religious elements, idea, emotion and rite, are all sunk and integrated into this worldly ethnics and daily physiological syntheses. Don't have to build another theology building. Based on this the psychological principle of this emotion, Confucius's thought of "being righteous" has highlighted democracy and humanitarianism in the primitive clan system. It starts from relative and then relates to others. Love our relatives and then love other people. It started from "love your closest relatives" in the blood patriarchy and then extended to "love people" (except for Yi and Di). Based on the bondage of blood tie, a humanistic relation of universal love was established between members of tribe in hierarchical order. This psychological basis has become management connotation and theoretical basis of Ding-style education mode.

In April 1998, when Mr. Ding Zuyi talked about the new ideas of teaching reform, he added a "whole-process" management on the basis of the original "full-time, full- 
residence, totally-enclosed, all-round" mode. In summary, it is now known as strict quasi-military "five-type" mode. In other words, it is close to the militarization management in contemporary military academies, and is quite different from the management of public universities. This strict quasimilitary management can be reflected in three aspects: first, it is reflected in the strict military training every year after the freshmen's enrollment in August. The week of military life can basically destroy students' finicky airs and stimulate them to endure hardships and help them establish confidence. Second, it is reflected in mandatory norms in their daily life system, such as, ten-forbid discipline (forbid them to fight, smoke, drink and fall in love). Third, it is reflected in severe punishment on students' deviant behaviors. If they refuse to mend their ways after repeated education, including cut classes for certain hours without reason, they will be expelled. Such severe punishment is to maintain the overall good teaching environment and order. This "five-type" quasi-military management is very different from the sacred rules of Buddhism and external binding of Mohist beliefs. It is a reflection of Confucianism and Confucian's positive life attitude. Its purpose is to reshape students' behavior and enhance their non-intelligence factors. This management mode is characterized by "strictness". It stresses management without love but education with love. It means to require students severely, teach students strictly and pursue study strictly. With Mr. Ding Zuyi as representative, we always follow the spirits of loving students like our children, never giving up and opening up. In the cultivation of students' comprehensive quality, we rely on collective power to restrict students' behaviors. With the training mode of "foreign language + profession + modernized skills", we strive to cultivate student into useful person for our modern construction.

Love is the core and tradition of Ding-style education mode. In the process of strict management, Mr. Ding Zuyi often warned his staff: "don't look at the crowded students here. Every child is treasured by parents and grandparents. They are very previous. We shall love them with responsibilities rather than considering them superfluous". He repeatedly stressed the view and concept of love, which enable the implementation of ten-forbid management under the guide of love. It has gained recognition and praise from parents and communities. "Ding-style education mode" was explored and summarized in the schooling practice of Mr. Ding Zuyi. It is a set of rich and fresh schooling experience. It contributes to Chinese civil education and the whole education system reform. It is crystal of wisdom from Confucian education and thousands of years of traditional Chinese education culture.

\section{CONCLUSION}

Zhongnan education culture has opened the most splendid page! After nearly thirty years of exploration and practice, Xi'an Fanyi University has developed into an outstanding comprehensive undergraduate university with a scope of more than 20000 students and nearly 200 thousand graduates. She has made great achievement in educational and teaching activities. The successor and honorary chairman Ding Jing and Chairman Zhang Shuiping and President Han Jiangshui and the new-generation leadership of Xi'an Fanyi University always adhere to the guidance of noble education and the schooling principle of non-for-profit public welfare and taken from students and used on students", and implement the applied talent training mode and quasi-military management mode of "foreign language + professional + modernized skills" and "professional + foreign languages + modernized skills". We have formed seven major schooling characteristics, including noble education concepts, Ding-style education mode, excellent foreign language talent training mode, unique style of student management mode, cooperation with foreign schools, actively building a modern university management system and management mode.

\section{REFERENCES}

[1] Shen Jiufu. Ding Zuyi and His Dream of Education. Xi'an: Shaanxi People's Publishing House, Mar. 2015.

[2] Chen Qingzhi. History of Chinese Education. Beijing: China Social Science Press, Jan. 2009.

[3] Li Zehou. History of Ancient Chinese Thought. Beijing: Life, Reading, New Knowledge Sanlian Bookstore, Jul. 2013.

[4] Li Zhihui. Study on Zhongnan Culture. Shaanxi Zhongnan Culture Research, Dec. 2016.

[5] Sun Peiqing. History of Chinese Education. Shanghai: East China Normal University Press, Mar. 2016. 